\title{
THE DIGITAL TAX SYSTEM IN THE LIGHT OF GDPR
}

\author{
Petra Žárská, Martin Daňko \\ Faculty of Law, Comenius University in Bratislava
}

\begin{abstract}
The digital tax system is becoming extremely essential in the modern world. As we look at the system itself as a great benefit for its users and states as well, we tend to forget the role of personal data within it. Personal data play crucial role in the errorless digital tax system. The new regulation of EU, General Data Protection Regulation is addressing processing of personal data within the state administration of EU member states. The aim of this article is to examine the effect of GDPR on the digital tax system and encourage wide academic and public discussion in relation to processing of personal data in the digital tax system.
\end{abstract}

Keywords: data protection, GDPR, tax, digital tax system, public tax authorities.

\section{INTRODUCTION}

State tax administrations are embracing the advantages of digital age at a steady speed. While some countries, such as the UK, are introducing digital tax system in April 2019, others are at the stage of planning. The Slovak Republic is carefully approaching the digital world by the means of informatization and adjusting existing services to digital users. Taking into account the undeniable benefits of the digital tax system, there are also substantial data protection issues to be solved. Considering the character of digital tax system, the following analysis of potential amendments to the tax system in relation to data protection might be needed. The inspiration has been found in the UK, which presents the vanguard of digital tax system in Europe. Firstly, the article will analyse requirements posed by GDPR ${ }^{1}$ in relation to the tax system of the Slovak Republic. Secondly, the UK's approach to chosen data subject's rights will be referred as an example of GDPR implementation. Thirdly, authors will suggest selected approaches to data protection issues involved in the future tax digital system of the Slovak Republic.

\section{THE GDPR REQUIREMENTS FOR THE TAX SYSTEM OF THE SLOVAK REPUBLIC}

Upon the qualification of public authorities and public tax authorities (further as "PTAs or PTA") as well ${ }^{2}$ as controllers or processors, ${ }^{3}$ in most cases GDPR burdens public authorities the same ob-

1 Regulation (EU) 2016/679 of the European Parliament and of the Council of 2burde7 April 2016 on the protection of natural persons with regard to the processing of personal data and on the free movement of such data, and repealing Directive 95/46/EC (General Data Protection Regulation).

2 We recognize tax public authorities a such Ministry of Finance of the SR, Financial Administration of the SR and many others which govern the tax system of the SR.

3 This article will not examine the roles of a recipient and third party due the complexity of the issue and will purely focus on the roles of a controller and processor. 
ligations as private companies, but some exceptions can be found. These exceptions prescribed by GDPR are related to the special character of public authorities connected to their role within a state administration. Additionally, previous data protection legislation had profound effect on data protection measures implemented by public authorities, there had been considerable compliance with the data protection legislation. The Act No. 122/2013 on data protection and amendments to certain acts (further "Act No. 122/2013") was rigid in the sense of obligations of legal entities processing personal data, therefore all legal entities had to amend some of existing obligations and comply with various new obligations in accord with GDPR. Although private companies and public authorities had abided the Act. No. 122/2013 and implemented many obligations, GDPR confers quite high numbers of new obligations. ${ }^{4}$ Authors will highlight all amended and new obligations of tax public authorities in following paragraphs.

\subsection{The controller's obligation to inform the data subject}

The controller's obligation to inform the data subject is governed by Article 12, 13 and 14 of GDPR. Article 12 of GDPR is regulating the obligations of controller (PTA) within providing any information referred to in Articles 13 and 14 and any communication under Articles 15 to 22 and 34 relating to processing to the data subject. This article replaced $\$ 29$ of Act No. 122/2013 and is more precise and detailed in comparison to previous legislation in terms of exercising the rights in art. 13, 14 and 15 to 22 and 34 of GDPR.

The right to information to be provided where personal data are collected from the data subject according to art. 13 of GDPR has to be exercised in accordance with art. 12 and also art. 13 of GDPR. Article 13 of GDPR prescribes the list of information provided to data subject at the time when personal data are obtained. The previous legislation was silent on the type of information provided to the data subject, therefore it is a partially new obligation for PTAs.

The only exception when the controller is not obliged to inform the data subject in accordance with article 13 is when the data subject already has the information. ${ }^{5}$

The controller's obligation to inform data subject where personal data have not been obtained from the data subject under art. 14 of GDPR is changed in the same fashion as the obligation under art. 13 of GDPR. The controller must provide the data subject with same information as information in article $13,{ }^{6}$ there is no obligation to inform about a processor and information has to be provided in accordance with art. 12 of GDPR, therefore in a concise, transparent, intelligible and easily accessible form, using clear and plain language. The instances for not informing the data subject where personal data have not been obtained from data subject are four under article $14 \mathrm{sec} .2$ point 5 while under article $13 \mathrm{sec} .4$ there is only one instance.

Some obligations have been updated, others have been added and certain obligations were abolished. The controller' obligation to inform data subject about a processor and the form of disclosure when personal data were to be disclosed is abolished by GDPR because it is replaced by providing

4 Transfer of personal data to third countries and international organisations, conditions applicable to child's consent in relation to information society services, a "purpose limitation" are not analysed in this article due to the complexity of these topic.

5 Art. 13 (4) of GDPR.

6 According to art. $14 \mathrm{sec} .2$ point $\mathrm{f}$ ) the controller has to provide information about the source from which the personal data originate, and if applicable, whether it came from publicly accessible sources. This information is not provided under art. 13. 
aforementioned information within the execution of right under art. 13 of GDPR. Within functioning of PTAs, the aforementioned changes will probably result into updating exiting informative forms or creating new forms for data subject across the whole tax system. In the digital tax system, the update of digital forms for informing data subject might be easier, quicker and cheaper due the character of tools used to manage the tax digital system. The update of general informative forms might be executed through the whole tax system by amending those forms by a "click". Subsequently the updated forms might be published on the websites of all PTAs or in the data subject's personal tax account, and put within all tax forms at the moment of filling of tax forms by a tax subject.

\subsection{The responsibility of controller and processor}

GDPR brought very wide range of amendments related to responsibility of controllers and processors. Article 26 of GDPR brings a new type of a controller, a joint controller, which administratively burdens those public tax authorities which found themselves to be joint controllers. Another administrative burden brought by GDPR is the amendment of a contract with a processor under art. 28 of GDPR. PTAs using processor have to take into account these amendments, update existing contract and apply new requirements to future processors.

All PTAs have obligation of appointing a data protection officer under art. 37 sec. 1 point a). The effect of new role within data protection is far reaching, it might have financial, administrative and personal impact on PTAs. GDPR offers to public tax authorities the possibility of a single data protection officer designated for several such tax authorities, taking into account its organisational structure and size. A single data protection officer for a group of PTAs would significantly decrease the burdening effect of this new role.

\subsection{The security of personal data}

The general obligation for the controller to take appropriate security measures is based on Art. 24 of GDPR in connection with Art. 32 to 34. Article 24 generally defines that the controller is obliged to implement appropriate technical and organizational measures to ensure and be able to demonstrate that the processing is carried out in accordance with GDPR and, if necessary, to review and update those measures. The measures should be based on the nature, scope, context and purpose of the processing, as well as on the risks with different likelihood and severity for the rights and freedoms of natural persons. Where appropriate in the light of processing activities, these measures include the introduction of adequate data protection policies by the controller.

Security measures include the adoption of appropriate technical, organizational and personnel security measures and guarantees by both the controller and the processor, which take into account, in particular, the principles of processing personal data such as the nature, scope, context and purposes of processing; resilience and recovery of processing systems, instructions of authorized persons, the adoption of appropriate measures to identify without delay the personal data protection breach and to promptly inform the regulator and the data subject; the adoption of appropriate measures to ensure the correction or erasure of incorrect data or other exercise of the rights of the data subject; and risks of different likelihood and severity for the rights and freedoms of data subjects. 
Implementing aforementioned measures means for public PTAs to re-evaluate existing security measure and implement new ones, such as pseudonymisation. All the measure are applicable within the digital tax system whereas the focus should be put on the digital security.

While security measures have been redesigned, the obligation of controller to develop a security project according to art. 20 of previous legislation, Act No. 122/2013, has been abolished by GDPR and replaced by the new obligation under art. 35 of GDPR. This new obligation of carrying out data protection impact assessment is binding for public tax authorities in three cases under art. $35 \mathrm{sec} .3$, therefore the authorities need to evaluate if they satisfy conditions in art. $35 \mathrm{sec} .3$ and if the answer is positive, those authorities are obliged to carry out data protection impact assessment.

When the public tax authority carries out data protection impact assessment which indicates that the processing would result in a high risk in the absence of measures taken by the controller to mitigate the risk, the public tax authority shall consult the supervisory authority prior to processing. To comply with this obligation, PTA might implement an internal process involving and executed by the data protection officer to analyse intended or actual data processing in regard to posing a high risk for the rights and freedoms of data subjects. This process should be kept active for future different data processing operations which need to be included into data protection assessment as well.

Along with implementing security measures, PTAS are obliged to keep records of processing activities. This is a new obligation under Art. 30 of GDPR replacing the registration obligation under Art. 43 of Act No. 122/2013. The obligation applies to the controller and the processor while previous legislation only required the evidential records from the controller. Records are kept in written form, including electronic form. For the purpose of demonstrating compliance with the GDPR, both the controller and the processor should keep records of the processing activities for which they are responsible under Art. 30 of GDPR. This article also defines the exact contents of the records. Keeping records of processing activities seems inevitable for all PTAs because the exception from this obligation under art. $30 \mathrm{sec} .5$ is not applicable to the most of PTAs. Also, the tax public authorities will have to amend the type of data contained in records because GPDR changed the data in records comparing to Act No. 122/2013.

Despite lawyers' perception of GDPR mostly as "added weight", the regulation abolished several obligations too. One of them is the notification obligation under articles 33 to 36 and registration obligation under articles 37 to 42 of Act No. 122/2013. PTAs are no longer obliged to notify and register information systems at the Office for Personal Data Protection of the Slovak Republic (further only "the Office").

Public tax authorities can abide all obligations posed by GDPR and the security of personal data can be breached despite all implemented measures. Under art. 33 of GDPR in the case of a personal data breach, the controller shall without undue delay and, where feasible, not later than 72 hours after having become aware of it, notify the personal data breach to the Office, unless the personal data breach is unlikely to result in a risk to the rights and freedoms of natural persons. Where the notification to the Office is not made within 72 hours, it shall be accompanied by reasons for the delay. The data subject is protected under art. 34 of GDPR. When the personal data breach is likely to result in a high risk to the rights and freedoms of natural persons, the controller shall communicate the personal data breach to the data subject without undue delay. The articles yield several consequences for PTAs. Firstly, under art. 33 sec. 5 of GDPR PTAs have to keep documentation about all personal data breaches. Secondly, PTAs should invent a mechanism of monitoring and notifying 
the data protection officer. The mechanism should be effective due to short time period of 72 hours. A supervising authority for all PTA is the Office based on article $55 \mathrm{sec} .2$ of GDPR.

Absolutely new tools to the data protection are codes of conduct (art. 40 of GDPR) and certifications (art. 42 of GDPR) which can be used by PTAs for proving the compliance with GDPR. PTAs or other public authorities can also fulfil a role of the certification bodies for controllers.

\subsection{Lawfulness of processing}

GDPR redesigned lawfulness of processing in a great depth. Article 6 of GDPR contains some of the previous legal basis for lawful processing such as a consent of data subject under art. 6 sec. 1 point a), while introducing a new legal basis for lawful processing such as "legitimate interest" under art. $6 \mathrm{sec} 1$ point $\mathrm{f}$ ) of GDPR. Certain previously binding legal basis were rescinded by GDPR such as legal basis under art. $10 \mathrm{sec} .3$ point d) "direct marketing in postal services", art. $10 \mathrm{sec} .3$ point e) "processing of previously published personal data", art. $15 \mathrm{sec} .4$ "one time entry" and art. $15 \mathrm{sec}$. 7 "monitoring of areas accessible to the public" of Act No. 122/2013. The effects of those amendments for PTAs are that PTAs are obliged to replace rescinded legal basis by new ones under article 6 of GDPR assuming that PTAs are willing to continue in these types of data processing. Given the character of rescinded legal basis, it can be replaced by legal basis under art. $6 \mathrm{sec} .1$ point c) "legal obligation" or under art. $6 \mathrm{sec}$. 1 point f) "legitimate interest". Updating legal basis according to art. 6 of GDPR also means for PTAs the update of privacy notice published in its official websites in order to fulfil the informative obligation against data subjects.

The consent of data subject has been also redesigned by article 7 of GDPR. The new legislation specifies the content and formalities of consent as a legal basis for the processing of personal data. Although PTAs might predominantly process personal data lawfully under art. $6 \mathrm{sec} .1$ point e) of GDPR, ${ }^{7}$ numerous instances of requiring the consent of data subject might occur within PTAs' wide area of activities. Given to the need of consent PTAs should send all eligible data subject a new redesigned consent and come up with a new update version of consent for future eligible data subject.

In connection to data of a deceased person, GDPR repeals the provision of $\$ 12$ par. 7 of Act No. 122/2013 "processing the personal data of a deceased person". In cases where PTAs processed data of a deceased person, PTAs should not continue in processing or replace the rescinded legal basis by suitable legal basis under art. 6 of GDPR.

A high number of public authorities, including PTAs, process special categories of personal data. GDPR brings in Art. 9 sec. 2 legal basis superseding the general prohibition on the processing of specific categories of personal data which means that PTAs are obliged to re-evaluate processing of special categories of personal data and update legal basis in accordance with GDPR.

The usefulness of automated processing for the digital tax system is undeniable, therefore, PTAs must consider new legislation under article 22 of GDPR. Although art. 22 present general prohibition of automating processing, including profiling, there are certain exemptions. One exemption is that automated processing including profiling is allowed by GDPR when it is authorised by Union or Member State law to which the controller is subject and which also lays down suitable measures to safeguard the data subject's rights and freedoms and legitimate interests. PTAs are allowed to

Processing is necessary for the performance of a task carried out in the public interest or in the exercise of official authority vested in the controller. 
conduct automated processing in the course of executing its legal obligations required by current legislation of the Slovak republic and EU, and PTAs also must implement safeguard measures for data subject's rights and freedoms and legitimate interests.

\subsection{Rights of data subject}

Rights of data subject have been significantly revamped by GDPR. The right to rectification under article of GDPR is more precise than the same right under art. $28 \mathrm{sec}$. 1 point e) of Act No. 122/2013. Without undue delay PTAs are obliged to provide data subject with the rectification of inaccurate personal data concerning him or her. Within this right PTAs are also obliged to replenish incomplete personal data, including by means of providing a supplementary statement.

Although GDPR brought a new right to erasure (right to be forgotten) under art. 17, PTAs are not burdened by the execution of this right mainly when its processing is necessary for compliance with a legal obligation which requires processing by Union or Member State law to which the PTA is subject or for the performance of a task carried out in the public interest or in the exercise of official authority vested in the PTA or for archiving purposes in the public interest, scientific or historical research purposes or statistical purposes. Art. $17 \mathrm{sec} .3$ offers additional conditions under which PTAs are not legally bound to exercise this right.

Another new right embedded in GDR is the right to restriction of processing under art. 18. When processing is restricted in accord with conditions lay down in art. $18 \mathrm{sec} .1$, PTAs are allowed to process personal data only with the data subject's consent or for the establishment, exercise or defence of legal claims or for the protection of the rights of another natural or legal person or for reasons of important public interest of the Union or of a Member State. PTAs are obliged to inform the data subject when the restriction of processing is lifted.

Article 20 of GDPR introduced new right to portability. PTAs are not obliged to exercise this right when they perform or carry out tasks in the public interest or in the exercise of official authority vested in the PTAs.

Alongside the right to rectification, erasure and portability, GDPR serves the data subject with the right to object under art. 21, where data subjects can object processing of personal data concerning him or her which is necessary for the performance of a task carried out in the public interest or in the exercise of official authority, or necessary for the purposes of the legitimate interests pursued by the controller or by a third party. PTAs can carry out processing of personal data even after the objection of data subject when PTAs demonstrate compelling legitimate grounds for the processing which override the interests, rights and freedoms of the data subject or for the establishment, exercise or defence of legal claims.

An extremely heavy burden for PTAs might be the notification obligation under art. 19 of GDPR. PTAs shall communicate any rectification or erasure of personal data or restriction of processing carried out to each recipient to whom the personal data have been disclosed, unless this proves impossible or involves disproportionate effort. The PTA shall inform the data subject about those recipients only if the data subject requests it. 


\subsection{The approach of $\mathrm{HMRC}^{8}$ to controller's obligation to inform data subject}

Authors consider the HMRC approach to the digital tax system as the most progressive and suitable to inspire PTAs in the Slovak republic. Firstly, around 2015 HMRC launched a package of six consultations ${ }^{9}$ which aim to design tax system around people it affects. These consultations are to discuss all the aspects of the tax system, including its digital character and therefore the use of personal data in digital era. Within consultations, citizens (data subjects) were able to input their suggestions in the process of creating digital tax system and became aware of data protection as well. Secondly, in the second stage of creating functioning digital tax system, HMRC introduced "Making Tax Digital". "Making Tax Digital is a key part of the government's plans to make it easier for individuals and businesses to get their tax right and keep on top of their affairs. HMRC's ambition is to become one of the most digitally advanced tax administrations in the world." ${ }^{10}$ Making Tax Digital is focusing on VAT and incomes. Under this digital tax system, digital VAT returns will be required from 1 April 2019. It will be a pilot system opened to around half a million businesses. In connection to the controller's obligation to inform data subjects, authors would like to highlight "HMRC privacy notice"11 which is a website dedicated to fulfilling all PTAs informative obligations under art. 12, 13 and 14 of GDPR and related articles. This privacy notice presents a practical way of accommodating the right to be informed and to access personal data. Authors highly recommend to all PTAs to go through the website and make good use of presented notice.

\section{CONCLUSION}

GDPR brought many amendments to the data protection in the hands of PTAs. Authors are of opinion that the digital tax system is better equipped to carry out obligations stemming from new legislation because the system can process an enormous extent of personal data need in taxation by using automated processing of personal data. Additionally, the tax digital system is able to publish all required forms online, such as consent, a form to object, a form for informing the data subject when the restriction of processing is lifted, a form to rectify or erase personal data and other forms required by GDPR. Online filling of these forms might speed up the process of taxation and minimise misuse of personal data. The possibility of unification of those forms for the PTAs conducting the same activity might also be easily implemented within the digital tax system. Issuing certifications under art. 42 might be executed only in a digital form from the point of filling the form to the final point of granting a digital certificate. The possibility of digital tax system in data protection field are endless, PTAs could invent a digital process of informing the Office about data breach under art. 33 of GDPR. This process seems to be effective due to the short reactive time of 72 hours.

8 HMRC stands for Her Majesty's Revenue and Customs. HMRC is responsible for the collection of taxes.

9 Available at: https://www.gov.uk/government/collections/making-tax-digital-consultations (accessed on $5^{\text {th }}$ November 2018).

10 https://www.gov.uk/government/publications/making-tax-digital/overview-of-making-tax-digital\#income-tax (accessed on $5^{\text {th }}$ November 2018).

11 https://www.gov.uk/government/publications/data-protection-act-dpa-information-hm-revenue-and-customs-holdabout-you/data-protection-act-dpa-information-hm-revenue-and-customs-hold-about-you (accessed on $5^{\text {th }}$ November 2018). 
The biggest challenge for the digital tax system might be a security of personal data. PTAs must employ effective security measure, be it virtual such as firewall or physical such as securing hardware in special locations as well. A very important role plays the awareness of public towards data protection, where educating public about possible threats is a firm practice of HMRC. ${ }^{12}$

Authors are of opinion that thorough implementation of GDPR obligations tailored to need of PTAs, a healthy inspiration by HMRC's practice and education of tax payers is the best way of creating the secure and effective digital tax system in the Slovak Republic.

\section{Bibliography:}

HUDECOVÁ, I. et al.: Regulation on the protection of natural persons with regard to the processing of personal data GDPR. Commentary. Bratislava: Eurokódex, 2018. 700 pages.

NULÍČEK, M. et al.: GDPR. General regulation on the protection of personal data. Commentary. Praha: Wolters Kluwer, 2017. 544 pages.

NARVADHA, V. - ROBIN, N. - YOGESH, K. D.: What determines success of an e-government service? Validation of an integrative model of e-filing continuance usage. In: Issues Government Information Quarterly, Vol. 35, 2018, pp. 161-174.

BERNARDO, D. O.: Technological innovation within the Spanish tax administration and data subjects' right to access: An opportunity knocks. In: Computer Law \& Security Review, Vol. 34, 2018, pp. 628-639.

\section{Contact information:}

Mgr. Martin Daňko, PhD.

martin.danko@flaw.uniba.sk

Faculty of Law, Comenius University in Bratislava

Šafárikovo nám č. 6 ,

81000 Bratislava 1

Slovakia

Mgr. Petra Žárská, LL.M

petra.zarska@flaw.uniba.sk

Faculty of Law, Comenius University in Bratislava

Šafárikovo nám č. 6,

81000 Bratislava 1

Slovakia

12 https://hmrcdigital.blog.gov.uk/2018/06/12/combating-scamming-the-latest-threat-to-hmrc-customers/ (accessed on $5^{\text {th }}$ November 2018). 